\title{
Sensitization to Allergen Components from Natural Rubber Latex (Hevea Brasiliensis) in A 15-Year Old Girl Undergoing Multiple Surgical Procedures
}

\author{
Shigemi Yoshihara*, Motoko Nakayama, Masaya Kato, Yusuke Ando, Manabu Miyamoto, Abid Hamid, Hironobu Fukuda
}

Department of Pediatrics, Dokkyo Medical University, Tochigi, Japan

\begin{abstract}
$\underline{\text { Abstract }}$
This paper describes a case of anaphylaxis due to latex exposure during surgery. Allergic reactions to latex during surgery have been described in spinal bifida patients. The case presented in our manuscript is a 15-year old girl who experienced an anaphylactic reaction during her 12th surgery of giant hairy nevus on the thigh. She had a history of oral pruritus after ingestion of chestnut suggesting latex-fruit syndrome. Specific IgE was positive to latex and the allergen components Hev b 1, 3, 5 and 6.02. The diagnosis was latex-allergy due to sensitization obtained after multiple surgeries, possibly due to the contact of latex-containing gloves. Anaphylactic shock during surgery due to NRL allergy is being reported continuously. To prevent allergic reactions during surgery in patients who undergo multiple surgeries, not only in Spina Bifida (SB) patients, frequent analyses of specific IgE to NRL are essential as well as the documentation of the clinical history after ingestion of latex-fruit syndrome related foods. Measurement of specific IgE to allergen components from NRL might be useful in the diagnosis of NRL allergy and in the investigation of the route of NRL sensitization.
\end{abstract}

\section{Introduction}

The clinical history of latex-fruit syndrome related food reactions and frequent measurement of specific IgE to natural rubber latex are important to prevent allergic reactions during multiple surgeries. The specific IgE reactivity to latex components could explain the route of sensitization.

Sensitization to natural rubber latex (NRL) is an important cause of anaphylaxis in children requiring multiple surgeries. Those patients are repeatedly contacted with NRL from gloves and medical devices [1]. Skin prick test (SPT) and specific IgE antibody measurement to NRL are useful for diagnosing sensitization. However, these tests are not clinically specific due to presence of cross-reactive components in the NRL extract. Recently, specific IgE assays with allergen components from NRL are commercially available as research reagents. It is reported that measurements of specific IgE to some components from NRL were more specific than specific IgE to crude extract [2]. The sensitization pattern to these components differs among patients with NRL allergy [3].

\section{Case Report}

A 15-year old girl was referred to our allergy outpatient clinic for investigating a course of anaphylactic shock during her 12th surgery of giant hairy nevus on the thigh. She never had any allergic responses in the previous surgeries. General anesthesia was induced with remifentanil, ketamine and propofol. Lidocaine, Fosfomycin and amino-acid formula were also administrated. Two hours later, her blood pressure and arterial blood oxygen saturation decreased and then she developed a systemic wheal reaction. Immediately, adrenaline and methylprednisolone were administrated. About 2 minutes later, her blood pressure increased.

Initially, the cause of anaphylaxis was considered to be either lidocaine, amino-acid formula or Fosfomycin. SPT was performed with these 3 drugs. However, the SPTs were all negative. The patient had a history of oral pruritus after ingestion of chestnut. Reactions to other latex-fruit syndrome related foods were unclear. As chestnut has cross-reactive allergen components with NRL, we suspected NRL as the cause of the anaphylaxis. Specific IgE antibodies to NRL and latex components (Hev b 1, Hev b 3, Hev b 5, Hev b 6.02, Hev b 8, Hev b 9 and Hev b 11) were measured by ImmunoCAP (Thermo Fisher Sci- 
entific, Uppsala, Sweden). Specific IgE antibody titers to crude NRL, Hev b 1, Hev b 3, Hev b 5 and Hev b 6.02 were 76.1, 2.24, 34.3, 74.6 and $1.56 \mathrm{UA} / \mathrm{ml}$, respectively. Specific IgE to the other NRL components were negative (Table 1). From these results, the cause of anaphylactic shock was diagnosed as allergy to NRL due to sensitization after multiple surgeries.

\begin{tabular}{|c|c|}
\hline Allergen & Specific IgE titer $\left(\mathbf{k U _ { A }} / \mathbf{L}\right)$ \\
\hline Crude NRL & 76.1 positive \\
\hline Hev b 1 & 2.24 positive \\
\hline Hev b 3 & 34.3 positive \\
\hline Hev b 5 & 74.6 positive \\
\hline Hev b 6.02 & 1.56 positive \\
\hline Hev b 8 & $<0.1$ negative \\
\hline Hev b 9 & $<0.1$ negative \\
\hline Hev b 11 & 0.18 negative \\
\hline Negative: $<0.35$ kUA/L & \\
NRL: natural rubber latex & \\
\hline
\end{tabular}

Table 1: Results of specific IgE to NRL and latex components

After this fatal surgery, the patient has had 5 similar surgeries under a NRL-free environment and she never developed any further allergic reactions. As she has had systemic urticarial reactions after ingestion of yogurt containing mango and blueberries, she is eliminating foods related to latex-fruit syndrome from her diet.

\section{$\underline{\text { Discussion }}$}

NRL allergy has been recognized as a serious health problem. High risk factors of NRL allergy are congenital abnormality in the urinary system, neural tube anomaly such as spinal bifida (SB), multiple surgeries [4], occupational exposure, allergy to foods related to latex-fruit allergy, and history of allergic diseases. Management of patients with NRL allergy includes avoidance of NRL exposure. However, completely clearing of NRL from hospital environment is difficult due to its usability and cost issues.

The most common cause of anaphylaxis during anesthesia is reported to be muscle relaxant agents followed by NRL and antibiotics [5]. We initially performed SPTs to drugs for anesthesia, but all tests were negative. Many cases of NRL allergy in patients undergoing multiple surgeries have been reported. The concentration of specific IgE antibodies to NRL has been correlated with the number of surgeries in patients with SB. Having more than five surgeries significantly increases the risk of sensitization to NRL [4]. The patient described in this report has had oral pruritus after ingestion of chestnut. So, we suspected NRL as the cause of the anaphylactic shock despite her never having any allergic reactions during her previous 11 surgeries. Specific IgE to NRL and allergen components from NRL was measured. The patient was strongly sensitized to NRL (76.1 UA/ml), Hev b 3 (34.3 UA/ $\mathrm{ml})$ and Hev b $5(74.6 \mathrm{UA} / \mathrm{ml})$. Hev b 3 has been found to be an important allergen component in NRL-allergic patients with SB but not in health care workers (HCW) [6]. Hev b 5-specific monoclonal antibodies and human IgE from HCW with NRL allergy demonstrated a greater content of Hev b 5 in powdered glove extract [7]. Ylitato reported different IgE antibody patterns between NRL-allergic children who have not undergone surgery and those with multiple surgeries [3]. In the former cases, the major sensitizing components were $\mathrm{Hev}$ b 6.01 and $\mathrm{Hev}$ b 6.02, but not Hev b 1 . These findings were similar to the IgE sensitization pattern of allergic HCW. In patients with multiple surgeries, sensitization was predominately to $\mathrm{Hev} b 1$ and Hev b 3. Our conclusion from these results is that the patient described in this report might have been sensitized to NRL by multiple contacts with NRL gloves of the surgical staff.

Anaphylactic shock during surgery due to NRL allergy are continuously reported $[8,9]$. To prevent allergic reactions during surgery in patients who undergo multiple surgeries, not only in SB patients, frequent analyses of specific IgE to NRL are essential as well as the documentation of the clinical history after ingestion of latex-fruit syndrome related foods. Measurement of specific IgE to allergen components from NRL might be useful in the diagnosis of NRL allergy and in the investigation of the route of NRL sensitization.

\section{$\underline{\text { References }}$}

1. De Swert LF, van Laer KM, Verpoorten CM, van Hoeyveld EM, Cadot P, et al. (1997). Determination of independent risk factors and comparative analysis of diagnostic methods for immediate type latex allergy in spina bifida patients. Clin Exp Allergy 27: 1067-1076.

2. Yagami A, Suzuki K, Matsunaga K (2009) Hev b 6.02 is the most impotant allergen in health care workers sensitized occupationally by natural rubber latex gloves. Allergol Int 58: 347-355. [Crossref]

3. Ylitalo L, Alenius H, Turjanmaa K, Palosuo T, Reunala T (1998) $\mathrm{IgE}$ antibodies to prohevein, hevein, and rubber elongation factor in children with latex allergy. J Allergy Clin Immunol 102: 659664.

4. Michael T, Niggemann B, Moers A, Seidel U, Wahn U, et al. (1996) Risk factors for latex allergy in patients with spina bifida. Clin Exp Allergy 26: 934-939.

5. Michalska-Krzanowska G (2012) Anaphylactic reactions during anaesthesia and perioperative period. Anestezjol Intens Ter 44: 104-111. 
6. Yeang HY, Ward MA, Zamri AS, Dennis MS, Light DR (1998) Amino acid sequence similarity of $\mathrm{Hev} b 3$ to two previously reported 27 - and $23-\mathrm{kDa}$ latex proteins allergic to spina bifida patients. Allergy 53: 513-519.

7. Sutherland MF, Drew A, Rolland JM, Slater JE, Suphioglu C, et al. (2002) Specific monoclonal antibodies and human immunoglobulin E show that Hev b 5 is an abundant allergen in high protein powdered latex gloves. Clin Exp Allergy 32: 583-589.
8. Sekiya K, Watai K, Taniguchi M, Mitsui C, Fukutomi Y, et al. (2011) Latex anaphylaxis caused by a Swan-Ganz catheter. Intern Med 50: 355-357.

9. Yeh WS, Kiohara PR, Soares ISC, Carmona MJ, Rocha FT, et al. (2012) Prevalence of sensitivity signals to latex in meningomyelocele patients undergoing multiple surgical procedures. Rev Bras Anestesiol 62: 56-62. [Crossref]

Copyright: (C) 2019 Yoshihara S. This is an open-access article distributed under the terms of the Creative Commons Attribution License, which permits unrestricted use, distribution, and reproduction in any medium, provided the original author and source are credited. 